\title{
Géneros y Diversidad Sexual, por una Red Universitaria de diálogo y solidaridad
}

A unque los estudios de género llevan décadas de investigación y puesta en práctica, siguen irrumpiendo ciertos vacíos, y en ocasiones, una comprensión incompleta sobre significados y significantes fundamentales a la hora de entender estas problemáticas.

Si hablamos de "género", ¿estamos incluyendo a los hombres? Y si optamos por lidiar por la igualdad o equidad de género, según sea el caso, ¿qué género o géneros debemos tener en cuenta? ¿Qué pasa con "lo binario"? ¿Y con los miles de performances que porta la heteronormatividad? Hay quienes se hacen estas y muchas preguntas más; pero también hay quienes ni siquiera se las cuestionan.

Afortunadamente, y a partir del siglo pasado, el pensamiento, no sólo de intelectuales, sino también de muchas personas no dedicadas a lo académico, se dejó afectar - con todos y cada uno de los sentidos de este verbo- por las luchas feministas, la emergente perspectiva de género, el llamado de atención de la gente trans, la igualdad para las comunidades homosexuales, bisexuales, queer, entre otras.

Sin embargo, tanto las universidades como los gobiernos requieren de lapsos de análisis y posibles soluciones para determinar en qué consisten estas categorías, que aún no han terminado. Esta petición tiene su gran aspecto positivo. Las casas de estudio se han convertido en verdaderas hacedoras de una tarea titánica e imprescindible en estos tiempos, donde las poblaciones del mundo solicitan educación al respecto de estas dinámicas. De este modo, la educación superior, entre otras instancias educativas, es convocada a intervenir en esta exigencia de parte de quienes se interesan por hacer no sólo de las universidades, sino de nuestros espacios públicos y privados, lugares de bienestar.

Es por ello que una de las razones de este número de Universidades se cimienta, precisamente, en acercarse y profundizar sobre estos asuntos que nos están preocupando y ocupando en la actualidad: ¿por qué es imprescindible la transversalización de la perspectiva de género en la educación superior?, ¿qué tan grave es no discurrir sobre la interculturalidad y género de los y las estudiantes?, ¿de qué manera deben implementarse las políticas de género en nuestras universidades?, ¿cómo conocer lo que sucede en el interior de las instituciones de educación superior, concernientes a estas cuestiones?

Sí, somos parte de un momento privilegiado, pero también difícil. Nos encontramos en una transición que cruza una considerable cantidad de generaciones que permiten y, a la vez no, la fluidez de estos cambios tan venturosos e inexcusables. Existen personas que sí 


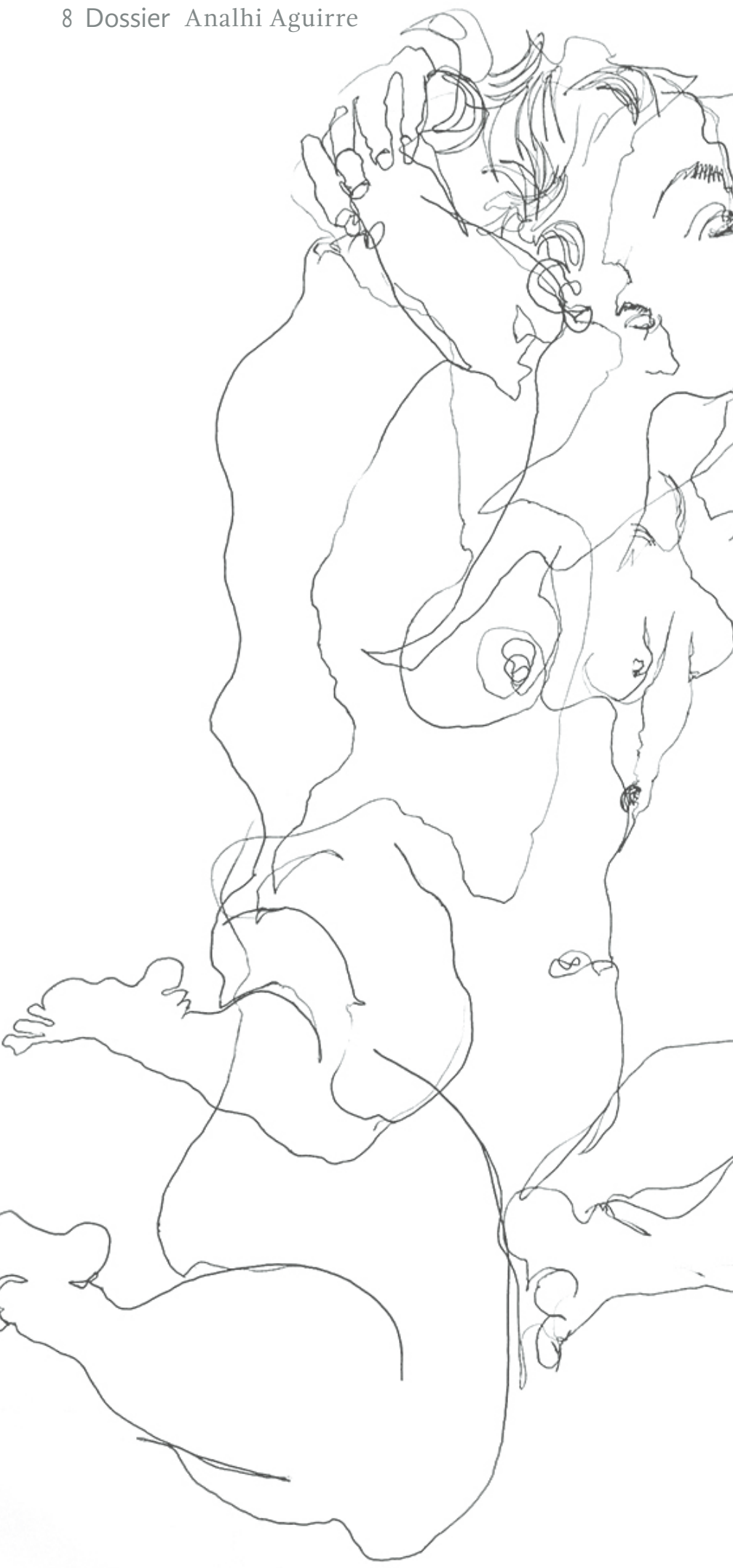

comprenden que estamos en una situación ineludible y justa para pensar, construir y reconstruir un presente con particularidades mejores para todo el mundo. No obstante, a diario, batallamos con quienes rechazan cualquier tipo de mutación social, aun cuando esta signifique vivir mejor.

Dentro de estos parámetros, las universidades siempre han sido un sitio óptimo para llevar estos cuestionamientos a investigación y examen, con la meta de llegar a resultados beneficiosos que se manifiesten como herramientas útiles, disponibles y comprensibles para la sociedad. Esta es una de las razones por las que la Unión de Universidades de América Latina y el Caribe creó la Red Universitaria de Géneros, Equidad y Diversidad Sexual (RUGEDS).

La demanda de acciones referidas a estas dinámicas por parte de las universidades hacia otras casas de estudio, organizaciones, estudiosos y estudiosas, en particular, solicita resolver ya las enormes dificultades que han enfrentado y enfrentan día a día respecto a la violencia de género, las desigualdades y falta de equidad de género, el agresivo desconocimiento que se revela ante las diversidades sexuales, la carencia de percepción desde las políticas académicas y públicas para apoyar a quienes se erigen como vínculos primordiales entre lo universitario, social y personal, y que ejercen de lazo indispensable a la hora de generar y proponer existencias más evolucionadas y contempladas desde un sentido común humano, sin sexismo, racismo, xenofobia, por mencionar sólo algunos de los obstáculos que nos inquietan.

Este ejemplar 81 de revista Universidades ha sido y es un instrumento vital para que nuestras universidades afiliadas se conozcan y comuniquen sus inconvenientes habituales sobre, por ejemplo, cómo formular un protocolo que actúe contra comportamientos que violenten a 
los géneros, donde, por supuesto, participan aspectos relacionados con las cuestiones de etnia, raza y clase social, y que por ende, no se hallan desligados de estas preocupaciones.

Cabe aclarar que la iniciativa de RUGEDS, como así también la de Universidades 81 , se asienta en que los géneros son más de dos (de ahí el atrevimiento de irrumpir con el plural de dicho término en el nombre de la Red), que los estudios de género no son solamente proyectos de y para las mujeres, que las determinaciones binarias deben reconocer que no son las únicas presentes, que las representaciones de la heteronormatividad motivan estructuras rígidas que se ponen de acuerdo con incuestionables sistemas de ideas, fundamentadas no precisamente en el bien común, sino, más bien, todo lo contrario...

Es por eso que, como coordinadora de la Red Universitaria de Géneros, Equidad y Diversidad Sexual, es un placer para mí presentar este Dossier que contiene colaboraciones indispensables como aporte a esta situación de emergencia y que tienen el propósito de favorecer la comprensión, la enseñanza y la toma de fuerzas para continuar trabajando en esta labor que hoy nos sitúa como factores sumamente implicados en las faenas de la educación superior de América Latina y el Caribe.

Los cuatro documentos que aquí se despliegan "Arando surcos: Incorporación de las mujeres indígenas como académicas en dos universidades públicas mexicanas", de Norma Molina Fuentes (Centro de Investigación de Estudios Avanzados del Instituto Politécnico); "La equidad de género en la educación intercultural del nivel superior: una mirada hacia el respeto de los derechos de las mujeres indígenas y afrodescendientes", de Nolvia Verónica López
Recinos (Universidad Pedagógica Nacional Francisco Morazán); "Proceso de transversalización de la perspectiva de género en la Universidad Autónoma de Ciudad Juárez. Avances y obstáculos", de Lorena Ortega Ayala (Universidad Autónoma de Ciudad Juárez); y "Los estudios de género en la UBA y la UNAM: una conquista del feminismo académico", de Gabriela Lozano Rubello (Universidad Autónoma Metropolitana); se complementan con otros igual de indefectibles que, asimismo, son muestras del interés y el esfuerzo de las universidades afiliadas a UDUAL $y$, en este caso, asociadas a la RUGEDS. Me refiero a la entrevista a Tiffany Mercado González, de la Universidad Nacional Autónoma de Nicaragua, el informe proporcionado por la Universidad Iberoamericana Ciudad de México-Tijuana, sobre la igualdad de género, la inclusión y la justicia social en su institución por Elvia González del Pliego Dorantes, el reporte acerca del Archivo Ana Victoria Jiménez del movimiento feminista en México (1970-1990) por Luis Héctor Inclán Cienfuegos, de la misma casa de estudio, la reseña sobre el reciente libro Igualdad sustantiva en las Instituciones de Educación Superior, de Beatriz Eugenia Rodríguez Villafuerte, como también al apoyo logístico y constante de la Universidad Nacional Autónoma de Avellaneda.

Así, Universidades 81 tiene, entre otras metas, afianzar los fines de la UDUAL, que aluden a forjar alianzas para atender situaciones como las expuestas en las páginas que siguen, además de hacerles saber a nuestras afiliadas que la Red Universitaria de Géneros, Equidad y Diversidad Sexual extiende el diálogo permanente y solidario con ustedes.

Analhi Aguirre

UDUAL 